for their establishment can be decided. In general, musculoskeletal as opposed to multisystem trauma is well managed at district general hospital level in Britain, and the Royal College of Surgeon's report may well have overestimated district general hospital requirements for regional trauma centres.

We thank Mrs B Davies for her help in preparing the manuscript.

1 Department of Health and Social Security. Hospit medical staffing-achieaing a balance: a plan for action. London: DHSS, 1987.

Roval College of Surgeons. Report of the working party on the management of patients with major injuries. London: RCS, 1988.

3 Buck N. Devlin HB, Lunn JN. Report of the contidential enquiry into perioperative deaths. London: Nuffield Provincial Hospitals Trust and the peroperame deaths

+ Trauma Subcommittee of the British Orthopaedic Association. The management of trauma in Great Briain. London: BOA, 1989.
5 Ramsay A NSW Doctor Journal of New South Wales branch of the Australian

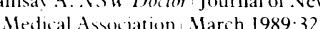

Civil ID), Schwab CW. The abbreviated injury scale, 1985 revision: a condensed chart for clinical use. F Trauma 1986;28:87-90.

7 Christian MS. Morbidity and mortality of car occupants: comparative survey over 24 months. Br.Med f 1984;289:1525-6.

8 West JG, Cales RH, Grazzaniga AB. Impact of regionalisation: the Orange County experience. Arch Surg 1983;188:740-4.

9 Eastman AB, Shackford SR, Hollingworth-Fridlund P, Cooper EN. The effect of regionalisation upon the quality of trauma care as assessed by concurrent audit before and after the institution of a trauma sistem; a preliminary report. 7 Trauma 1986;26:812-20.

10 Bull JP. The injury severity score of road traffic casualties in relation to mortality, time of death, hospital treatment time and disability. Accid Anal Prev $1975 \cdot 7 \cdot 2+9-55$.

11 Semmlow JL, Cone R. Utility of the injury severity score: a confirmation. Health Serv Res 1976;11:45-52.

12 Beverland DE, Rutherford WH. An assessment of the validity of the injury severity score when applied to gunshot wounds. Injury 1983:15:19-22.

13 MacKenzic EJ, Shapiro S, Eastham JN. Rating AIS severity using emergenc department sheets is inpatient charts. F Truuma 1985;25:984-8.

Accepled 15 December 1989
Welsh Hearing Institute, University Hospital of Wales, Cardiff CF4 4XW S D G Stephens, MRCP, audiological physician D E Callaghan, audiological technician

S Hogan, MSC, audiological scientist

$\mathrm{R}$ Meredith, audiological technician

A Rayment, hearing therapist

Medical Research Council Institute of Hearing

Research, University of Nottingham

A C Davis, PHD,

epidemiologist

Correspondence to: $\mathrm{Dr}$ Stephens.

Br.Med J 1990;300:508-11

\title{
Hearing disability in people aged 50-65: effectiveness and acceptability of rehabilitative intervention
}

\author{
S D G Stephens, D E Callaghan, S Hogan, R Meredith, A Rayment, A C Davis
}

\section{Abstract}

Objective-To determine the best means of detecting hearing disability in subjects aged 50-65 and whether rehabilitative intervention is acceptable in this age group.

Design-Questionnaire survey of patients on general practice age-sex registers. Two types of questionnaire were used, one being based on the closed set approach of the Institute of Hearing Research questionnaire, which had been used in a pilot study, and the other being a simplified version of this questionnaire developed by the Welsh Hearing Institute and based on open set questions. Questionnaires were sent up to three times, and any patients who had not responded two months after the last posting were personally contacted.

Setting-Two general practices in Glyncorrwg and Blaengwynfi in the Afan valley, West Glamorgan.

Patients - 271 Patients in Glyncorrwg (136 men, 135 women) and 333 patients in Blaengwynfi (173 men, 160 women) aged 50-65.

Interventions-All patients indicating hearing disability in answering the questionnaires were invited to attend for a evaluative session in their village. After audiometric testing advice and arrangements for fitting a hearing aid were offered as appropriate.

Main outcome measures-Response rates and prevalence of hearing disability before intervention and of possession of hearing aids before and after intervention.

Results-After three postings and personal contact the response rate was $\mathbf{9 8 \%}(\mathbf{2 6 6 / 2 7 1 )}$ in Glyncorrwg, where the complex questionnaire was used, and $97 \%$ (322/333) in Blaengwynfi. The prevalence of hearing disability was respectively $53 \%(141 / 266)$ and $46 \%$ $(148 / 322)$ and the prevalence of owning a hearing aid $7 \%(19 / 266)$ and $8 \%(24 / 322)$. After intervention the possession of hearing aids rose to $24 \%(64 / 266)$ in Glyncorrwg and $22 \%(71 / 322)$ in Blaengwynfi; six months later the aids were being used regularly. A direct comparison of the two questionnaires in 69 subjects from Blaengwynfi showed no significant differences in the amount of disability detected by each one. The first posting of questionnaires detected $65 \%(189 / 289)$ of the hearing disability in the two villages or $78 \%(72 / 92)$ of those prepared to accept hearing aids for the first time; $96 \%(88 / 92)$ of those who accepted hearing aids were detected by two postings.

Conclusions - Simple questionnaires are effective in detecting hearing disabilities in people aged 50-65, and intervention was acceptable in many of those who reported having difficulties in hearing. The response rates from successive postings suggest that two postings are sufficient in terms of the return in detecting those who will accept intervention.

\section{Introduction}

The average patient presenting at a hearing aid or rehabilitation clinic for the first time is aged about 70 years and has had hearing problems for about 15 years. ' By then the patient and his or her family have experienced considerable frustration because of this disability. Difficulties in adapting to new listening conditions and to handling hearing aids are more likely in such patients than in those presenting earlier.

One way of reducing this delay would be to introduce a secondary prevention programme by screening for hearing disability and impairment. The most effective people to target with such a programme are those aged 50-65, in whom the prevalence of hearing impairment and disability begins to increase noticeably. ${ }^{34}$ At an earlier age screening would not be cost effective because of the low prevalence. At a later age it would be too late.

We consequently performed a pilot study in suburban Cardiff in which we contacted patients aged 50-65 from a group practice age-sex register by either sending a disability questionnaire or performing domiciliary audiometric screening. Rates for the acceptance of hearing aids were similar with the two approaches, and after intervention the rate of using hearing aids rose from $3.5 \%$ to $8.9 \%$ in this population.

Several substantive and clinical problems were associated with the pilot study, and we extended it to a different population with a higher proportion of subjects from the manual social classes. We were also interested in comparing two types of screening questionnaire, a closed set approach as used previously ${ }^{5}$ and an open set question as used in the Cardiff health survey. ${ }^{+}$We therefore approached all patients aged 50 65 in two practices (Glyncorrwg and Blaengwynfi) in the upper Afan valley in West Glamorgan to determine the best techniques for detecting disability and to 
determine whether rehabilitative intervention is acceptable in such postindustrial populations.

Methods

SELECTION OF SUBJECTS

With the cooperation of the two general practitioners the age-sex registers were obtained for the two practices for patients aged 50-65. There were 271 in Glyncorrwg ( 136 men and 135 women) and 333 in Blaengwynfi ( 173 men and 160 women).

\section{SCREENING PROCEDURE}

The target population was invited to explanatory public meetings, which were well attended. Afterwards a letter was sent to the patients from the general practitioner outlining the aims of the study, together with a letter describing the potential benefits of early intervention; the disability questionnaire; and a prepaid reply envelope. The letters were sent up to three times at intervals of two months. Those who did not respond to the third posting within two months were contacted personally.

The questionnaire used in Glyncorrwg was identical with that used in the pilot study in Cardiff. A simplified questionnaire was used in Blaengwynfi (figure). ${ }^{+}$Half of the patients from Blaengwynfi who responded to the first posting were subsequently sent the questionnaire used in Glyncorrwg for purposes of direct comparison.

\section{CLINICAL AND AUDIOMETRIC PROCEDURES}

All patients indicating hearing disability or handicap in answering any of the criterion questions of the Glyncorrwg questionnaire or in questions 1 or 4 of the Blaengwynfi questionnaire were invited to attend for an evaluative session in their village. Firstly, a short clinical history was taken and a clinical examination performed. This was followed by audiometric testing and the completion of auditory disability and handicap questionnaires. All patients complaining of hearing difficulties whose hearing level in the worse ear exceeded a $30 \mathrm{~dB}$ loss (mean value over testing at 500 , 1000,2000 , and $4000 \mathrm{~Hz}$ ) were offered a fitting for a hearing aid, as were certain patients with a less severe hearing loss. Others who had lesser hearing losses or refused hearing aids were offered advice on hearing

TABLE I - Response rates and cumulative response rates to questionnaires in Glyncorrwg and Blaengwynfi. * Values are percentages (numbers)

\begin{tabular}{|c|c|c|c|c|}
\hline & \multicolumn{2}{|c|}{ Glyncorrwg $(n=271)$} & \multicolumn{2}{|c|}{ Blaengwynfi $(\mathbf{n}=333)$} \\
\hline & Response rate & $\begin{array}{l}\text { Cumulative } \\
\text { response rate }\end{array}$ & Response rate & $\begin{array}{l}\text { Cumulative } \\
\text { response rate }\end{array}$ \\
\hline \multicolumn{5}{|l|}{ Posting: } \\
\hline First & $71(191)$ & $71(191)$ & $51(170)$ & $51(170)$ \\
\hline Second & $14(37)$ & $84(228)$ & $26(88)$ & $78(258)$ \\
\hline Third & $8(22)$ & $92(250)$ & $11(37)$ & $89(295)$ \\
\hline Personal contact & $6(16)$ & $98(266)$ & $8(27)$ & $97(322)$ \\
\hline
\end{tabular}

${ }^{\star}$ Response rate to first posting in pilot study in Cardiff $=56 \%$ (189/338).

TABLE II - Prevalences of hearing disability, exposure to noise, and possession of hearing aids in respondents from Glyncorrwg and Blaengwynf. ${ }^{\star}$ V'alues are percentages (proportions)

\begin{tabular}{llllllll}
\hline & \multicolumn{3}{c}{ Glyncorrwg } & & \multicolumn{3}{c}{ Blaengwynfi } \\
\cline { 2 - 3 } & $\begin{array}{c}\text { Hearing } \\
\text { disability }\end{array}$ & $\begin{array}{c}\text { Exposure to } \\
\text { noise alone }\end{array}$ & $\begin{array}{c}\text { Possession of } \\
\text { hearing aid }\end{array}$ & & $\begin{array}{c}\text { Hearing } \\
\text { disability }\end{array}$ & $\begin{array}{c}\text { Exposure to } \\
\text { noise alone }\end{array}$ & $\begin{array}{c}\text { Possession of } \\
\text { hearing aid }\end{array}$ \\
\hline Posting & & & & & & & \\
$\quad$ First & $53(102 / 191)$ & $20(39 / 191)$ & $6(12 / 191)$ & & $51(87 / 170)$ & $20(34 / 170)$ & $6(11 / 170)$ \\
Second & $54(20 / 37)$ & $22(8 / 37)$ & $14(5 / 37)$ & & $42(37 / 88)$ & $24(21 / 88)$ & $10(9 / 88)$ \\
Third & $46(10 / 22)$ & $32(7 / 22)$ & $5(1 / 22)$ & & $38(14 / 37)$ & $24(9 / 37)$ & $8(3 / 37)$ \\
Personal contact & $56(9 / 16)$ & $19(3 / 16)$ & $6(1 / 16)$ & & $37(10 / 27)$ & $30(8 / 27)$ & $4(1 / 27)$ \\
\hline Total & $53(141 / 266)$ & $21(57 / 266)$ & $7(19 / 266)$ & $46(148 / 322)$ & $22(72 / 322)$ & $8(24 / 322)$
\end{tabular}

*In pilot study in Cardiff prevalences at first posting were: hearing disability $32 \%(108 / 338)$, exposure to noise alone $12 \%(40 / 338)$, and possession of hearing aid $4 \%(12 / 338)$.
Welsh Hearing Institute

Name: Date:-

PLEASE COMPLETE ALL THE QUESTIONS BY CIRCLING THE APPROPRIATE ANSWER.

1 Do you have any difficulty with your hearing?

1 No 2 Yes

If "Yes" please make a list of the difficulties which you have with your hearing. List these in order of importance starting with the biggest difficulties. Write down as many as you can think of.

2 Have you ever had a hearing aid? $1 \mathrm{No} 2 \mathrm{Yes}$

3 Do you use a hearing aid nowadays? 1 No 2 Yes

4 Do you have problems with noise(s) in your ear(s) or head?

1 No 2 Yes

If "Yes" please make a list of the problems which you have because of the noise(s). List these in order of importance starting with the biggest difficulties. Write down as many as you can think of.

5 Do you have any other problems with your ears?

1 No 2 Yes

If "Yes" please make a list of the problems which you have in order of importance starting with the biggest problems. Write down as many as you can think of.

6 Do you have problems as a result of giddiness or dizziness?

1 No 2 Yes

If "Yes" please make a list of the problems which you have in order of importance starting with the biggest problems. Write down as many as you can think of.

7 In which year were you born?

8 Are you

1 Female? 2 Male?

9 What has been your main occupation?

10 If you are married, what has been your husband's or wife's main occupation?

11 Did any of your parents, grandparents, children, brothers, or sisters have difficulty with their hearing before reaching the age of 65 ?

$$
1 \text { No } 2 \text { Yes } 3 \text { Don't know }
$$

12 How long altogether have you worked in noisy places where you had to shout to be heard?

1 Never 2 Less than 6 months 3 For 6-11 months 4 For $1-5$ years 5 More than 5 years

Welsh Hearing Institute questionnaire sent to subjects in Blaengwynfi. This is based on open set question as used in Cardiff health survey

tactics and environmental aids. Those who had treatable ear disease or required further investigation were either treated directly, in liaison with the general practitioners, or appropriately referred.

Patients fitted with hearing aids were followed up until it was clear that they were managing well. They were further evaluated six months after the fitting session.

\section{Results}

RESPONSE RATES AND PREVALENCE OF DISABILITY

Table.I shows the reponse rates in the two villages in relation to the three postings and the personal follow up. Apart from a comparatively low response rate in Blaengwynfi to the first posting, overall response rates were broadly similar.

Table II shows the proportions and percentages of those indicating hearing disability, those who had no disability but were exposed to considerable occupational noise, and those who had hearing aids at 
TABLE III - Possession of hearing aids in target population and among those indicating hearing disability in Cardiff, Glyncorrig, and Blaengwynfi before ${ }^{\star}$ and after intervention. V'alues are precentages (proportions)

\begin{tabular}{|c|c|c|c|c|c|c|c|c|}
\hline & \multicolumn{4}{|c|}{ Before intervention } & \multicolumn{4}{|c|}{ After intervention } \\
\hline & \multicolumn{2}{|c|}{ Target population } & \multicolumn{2}{|c|}{ Those indicating hearing disability } & \multicolumn{2}{|c|}{ Target population } & \multicolumn{2}{|c|}{ Those indicating hearing disability } \\
\hline & $\begin{array}{l}\text { First posting } \\
\text { only }\end{array}$ & Final follow up & $\begin{array}{c}\text { First posting } \\
\text { only }\end{array}$ & Final follow up & $\begin{array}{c}\text { First posting } \\
\text { only }\end{array}$ & Final follow up & $\begin{array}{l}\text { First posting } \\
\text { only }\end{array}$ & Final follow up \\
\hline Cardiff & $4(12 / 338)$ & - & $11(12 / 108)$ & - & $9(30 / 338)$ & - & $28(30 / 108)$ & - \\
\hline Glyncorrwg & $6(12 / 191)$ & $7(19 / 266)$ & $12(12 / 102)$ & $13(19 / 141)$ & $26(49 / 191)$ & $24(64 / 266)$ & $48(49 / 102)$ & $45(64 / 141)$ \\
\hline Blaengwynfi & $7(11 / 170)$ & $8(24 / 322)$ & $13(11 / 87)$ & $16(24 / 148)$ & $27(46 / 170)$ & $22(71 / 322)$ & $53(46 / 87)$ & $48(71 / 148)$ \\
\hline
\end{tabular}

TABLE IV-Comparison of Institute of Hearing Research questionnaire (originally sent to subjects in Glyncorrwg) with Welsh Hearing Institute questionnaire (figure) (sent to subjects in Blaengwynfi) in 69 subjects from Blaengwynfi. Values are numbers of subjects

\begin{tabular}{lcccc}
\hline & \multicolumn{4}{c}{ Welsh Hearing Institute questionnaire } \\
\cline { 2 - 5 } Institute of Hearing & No disability & Disability or handicap & Noise exposure & Total \\
\hline Research questionnaire & 16 & 4 & 0 & 20 \\
No disability & 1 & 36 & 3 & 40 \\
Disability or handicap & 2 & 2 & 5 & 9 \\
Noise exposure & 19 & 42 & 8 & 69 \\
\hline Total & & &
\end{tabular}

the different postings. There were no significant differences in the prevalence of disability, exposure to noise, or possession of hearing aids between the two villages. Analyses also indicated that the only significant difference between the first and successive postings was that subjects from Blaengwynfi responding to the first posting were more likely to report hearing disability than those responding to successive postings $\left(\gamma_{*}^{2}=9 \cdot 05\right.$, $\mathrm{df}=3 ; \mathrm{p}<0.05)$. The same questionnaire was used in Glyncorrwg as in the pilot study in Cardiff, and considerable differences were found in the responses of these two populations. Only $32 \%$ of the patients in Cardiff indicated disability and handicap compared with $53 \%$ in Glyncorrwg on the first posting $\left(\chi^{2}=23 \cdot 5\right.$, $\mathrm{df}=1 ; \mathrm{p}<0.001)$. Similarly, more patients in Glyncorrwg reported significant occupational exposure to noise $\left(\chi^{2}=7 \cdot 08, \mathrm{df}=1 ; \mathrm{p}<0 \cdot 01\right)$.

\section{UPTAKE OF HEARING AIDS}

Table III shows the possession of hearing aids before and after intervention in the populations from Blaengwynfi, Glyncorrwg, and Cardiff.' The values for people of the same age in the national study of hearing conducted in south Wales ${ }^{6}$ are also given. The initial use of hearing aids in Glyncorrwg and Blaengwynfi was significantly higher than that in the national study of hearing $\left(\chi^{2}=8 \cdot 7, \mathrm{df}=1 ; \mathrm{p}<0 \cdot 001\right)$. The figures show a threefold increase in the possession of hearing aids after intervention, but the absolute increase was higher in the Afan valley than in Cardiff (7\% (43/588) to 23\% (135/588) compared with $4 \%(12 / 338)$ to $9 \%(30 / 338)$ $\left(\chi^{2}=35.3, \mathrm{df}=2 ; \mathrm{p}<0.001\right)$. Similarly, the use of hearing aids as a function of reported hearing disability and handicap was significantly higher after intervention in Glyncorrwg than in Cardiff, where the same questionnaire was used $\left(\chi^{2}=9 \cdot 2, \mathrm{df}=1 ; \mathrm{p}<0.01\right)$.

In Glyncorrwg and Blaengwynfi $96 \%(88 / 92)$ of the aids were fitted to patients responding to the first and second postings and $78 \%(72 / 92)$ were fitted to those responding to the first posting. The motivation and attendance rates for those responding to the third posting and personal follow up were low.

\section{COMPARISON OF QUESTIONNAIRES}

No significant differences were found between Glyncorrwg and Blaengwynfi in the sex ratio $50 \% v$ $52 \%$ men respectively), social class $(88 \%$ v $\quad 89 \%$ manual), or exposure to occupational noise $(48 \% v$ $49 \%$ over five years). Therefore, the prevalence of hearing disability in the two populations would be expected to be broadly similar, and in fact the overall prevalence of disability shown in the two types of questionnaire did not differ significantly between Glyncorrwg and Blaengwynfi (table II).

Similarly, a direct comparison of the questionnaires in the same subjects from Blaengwynfi $(n=93,69$ responded $(74 \%$ response rate) ) showed no significant difference between the amount of disability detected with the two questionnaires (table IV).

\section{Discussion}

We were able to detect comparatively mild hearing difficulties in a preretirement working class population by using simple questionnaires. In addition, early intervention with hearing aids was acceptable in a high proportion of those who reported having hearing problems. This was true for the questionnaire based essentially on two open ended questions used in Blaengwynfi as well as the more detailed questionnaire used in Glyncorrwg.

The use of hearing aids after intervention constituted between a fifth and a quarter of the total target population or nearly half of those indicating hearing disability. When hearing aids are used so much by comparatively young people the stigma of hearing disability and of using hearing aids is reduced. This has been shown by the fact that many patients younger and older than the study group have asked for help. Follow up six months after intervention showed that all but one of the patients continued to use their aids. Furthermore, the mean hearing levels in the better ear of those accepting hearing aids were $30.0 \mathrm{~dB}$ (SD $10.8 \mathrm{~dB})$ in Glyncorrwg and $29.9 \mathrm{~dB}(11.0 \mathrm{~dB})$ in Blaengwynfi, considerably less than those presenting to ear, nose, and throat clinics for hearing aids. ${ }^{5}$ The hearing levels of those accepting and refusing aids are discussed elsewhere. ${ }^{\circ}$

The use of successive postings of questionnaires shows the diminishing returns of such an approach. Sixty five per cent of those with a hearing disability were detected with the first posting, or $78 \%$ of those prepared to accept hearing aids. Similarly, $96 \%$ of those accepting hearing aids were detected by two postings. Thus it seems reasonable to conduct no more than two postings of questionnaires. In a previous study we examined the value of intermediate indicators as determinants of which of those subjects indicating disability on a questionnaire will ultimately be offered and accept a hearing aid. ${ }^{7}$ We found that the result of the forced whisper test at $0.7 \mathrm{~m}$ was one of the best predictors. Therefore, an effective approach to the early detection of hearing disability and those prepared to accept hearing aids might be for general practitioners to send a simple one page questionnaire to people of retirement age and conduct a forced whisper test on patients indicating a hearing disability. Either one or two postings could be used according to the pick up rate considered to be worth targeting.

We thank the staff of Glyncorrwg and Blaengwynfi health centres, particularly Julian and Mary Tudor Hart, Cath 
Edwards, and Brian Gibbons, for their cooperation and support.

I Stephens SDG, Barcham LJ, Corcoran AL, Parsons N. Evaluation of an auditory rehabilitation scheme. In: Taylor IG, Markides A, eds. Disorders of auditory function III. London: Academic Press, 1976:265-73.

2 Brooks DN. The use of hearing aids by the hearing impaired. In: Stephen SDG, ed. Disorders of auditory function II. London: Academic Press, SDG, ed. D

Davis A. The epidemiology of hearing disorders. In: Hinchcliffe R, ed. Hearing and balance in the elderly. Edinburgh: Churchill Livingstone, 1983:1-43.
+ Stephens SDG. Lewis PA, Charny SC, Farrow SC, Francis M. Characteristics of self-reported hearing problems in a community surves. Audiology (in press

5 Davis AC. Epidemiology of hearing disorders. In: Stephens D, ed. Scot Brown's otolaryngologv. 5th ed. Vol 2. London: Butterworth, 1987:90-126.

6 Stephens SDG, Meredith R, Callaghan DE, Hogan S, Rayment A. Early intervention and rehabilitation: factors influencing outcome. Actu Otolaryngol intervention and re

7 Davies JE. John DG, Stephens SDG. Intermediate hearing tests as predictors of hearing aid acceptance. Clin Otolurngol (in press).

Accepted 15 December 1989

\section{Autonomic neuropathy after treatment with cisplatin, vinblastine, and bleomycin for germ cell cancer}

\author{
Steen Werner Hansen
}

Department of Oncology, Finsen Institute,

Rigshospitalet, DK 2100 Copenhagen, Denmark Steen Werner Hansen, $\mathrm{MD}$, clinical research assistant

Br.Med f 1990;300:511-2
Diseases and poisons that affect the peripheral nervous system can cause dysfunction of the autonomic nerves. ${ }^{\prime}$ Cytotoxic treatment with cisplatin or vinca alkaloids, or both, can have this complication.' Most patients with germ cell cancer treated with cisplatin and vinca alkaloids are cured, and thus knowledge of the prevalence and degree of autonomic neuropathy in these patients is important. I performed a study to investigate this.

\section{Patients, methods, and results}

All patients referred to this institute with metastatic germ cell cancer between March 1979 and December 1983 were treated with six courses of cisplatin, vinblastine, and bleomycin. Patients in whom a lasting complete remission occurred and who did not have

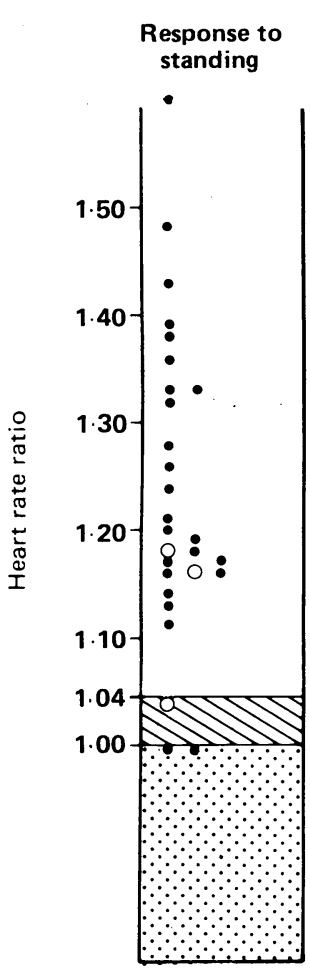

evidence of disease causing neuropathy were asked to participate in an examination of the functioning of their autonomic nerves. Informed consent was obtained from all patients. The heart rate response to Valsalva's manoeuvre, standing up, and deep breathing was used to evaluate function of the parasympathetic nerves, ${ }^{2}$ and function of the sympathetic nerves was assessed by measuring the postural changes in blood pressure. The results were analysed by using values recommended by Ewing and Clarke. ${ }^{2}$

Thirty four patients were eligible for the study, of whom six declined to participate. The 28 patients studied had a median age of 35 (range 19-55) years and had been followed up for a median of 83 (range 60-116) months. The only complaint related to autonomic dysfunction was impotence, which was found in three patients. Retroperitoneal lymph nodes were not dissected in any patient.

The figure shows the results of the three tests of functioning of the parasympathetic nerves. Minimal damage (one abnormal result) was found in eight patients; two of these patients, one of whom was impotent, yielded a borderline abnormal result in one of the two other tests. Two patients had two abnormal results, indicating definitive damage to the parasympathetic nerves, and one of these patients was also impotent. Eighteen patients showed no sign of dysfunction of the parasympathetic nerves, but in two of these the result of one test was borderline abnormal. Postural hypotension was not seen in any patient, although a borderline abnormal decrease in systolic pressure occurred in eight patients.

\section{Comment}

Most patients treated with cisplatin, vinblastine, and bleomycin have a peripheral sensory neuropathy of the "dying back" type affecting both large and small fibres. ${ }^{3}$ Conditions affecting small fibres are most likely to cause autonomic dysfunction, ' and it is therefore not surprising that we observed dysfunction of the parasympathetic nerves in 10 patients. Peripheral sensory neuropathy may also explain the impotence in two of the three patients who were affected. This is important, as most doctors believe that impotence is a psychological effect of the diagnosis and treatment of testicular cancer. Furthermore, the autonomic dysfunction may become disabling when these patients are aging as it is thought to play an important part in dysfunction of the bladder, postural hypotension, and thermoregulatory insufficiency in the elderly.

None of the patients we studied had postural hypotension, and this accords with the observation that postural hypotension is uncommon in "dying back" neuropathies that affect the large fibres of the long nerves. ${ }^{\prime}$ Cardiorespiratory arrests have occurred in patients with diabetes mellitus and autonomic dysfunction, often during or immediately after anaesthesia. ${ }^{+}$Sudden deaths that occur in patients treated with cisplatin, vinblastine, and bleomycin are believed to be caused by vascular toxicity ${ }^{5}$ but may in fact be caused by autonomic dysfunction. as ratio of heart rate $30 \mathrm{~s}$ after standing to that $15 \mathrm{~s}$ after standing), I'alsalva's manoeuvre (measured as of maximum heart rate to heart rate at rest), and deep breathing (measured as increase in heart rate).

Hatched areas indicate borderline abnormal values, stippled areas indicate abnormal values. $\mathrm{O}=$ Patients with impotence 